\title{
Políticas públicas de combate ao analfabetismo no Brasil: uma investigação sobre a atuação do Programa Brasil Alfabetizado em municípios do Ceará
}

\author{
Gleison Mendonça Diniz \\ Universidade de Fortaleza (Unifor) \\ Diego de Queiroz Machado \\ Universidade de Fortaleza (Unifor) \\ Heber José de Moura \\ Universidade de Fortaleza (Unifor)
}

\begin{abstract}
Este estudo tem por objetivo analisar as características do Programa Brasil Alfabetizado (PBA) em municípios do estado do Ceará que aderiram ao programa. Para tanto, foram selecionados, mediante critérios estatísticos de representatividade, 15 municípios do estado que aderiram ao programa. Os dados foram coletados junto aos alfabetizadores do PBA desses municípios, mediante preenchimento de questionário estruturado, e analisados por meio da técnica de análise de conglomerados. Com a separação dos municípios em grupos distintos, os achados apontaram divergências em relação a: critérios de seleção dos alfabetizadores e sua participação em cursos de formação; carga horária, material didático e instrutores dos cursos de formação dos alfabetizadores; frequência da coordenação dos cursos; duração do curso para alfabetização dos alunos; existência de programas para deficientes visuais e auditivos; e evasão e continuidade dos estudos dos alunos alfabetizados. Portanto, tais resultados possibilitaram observar as seguintes necessidades de fortalecimento quanto ao PBA: formação contínua de seus alfabetizadores; criação de programas para portadores de deficiência visual e auditiva; aprimoramento do acompanhamento das coordenações dos cursos; e combate aos altos índices de evasão por parte dos alunos matriculados.
\end{abstract}

Palavras-chave: política pública; analfabetismo; Programa Brasil Alfabetizado.

Políticas públicas para combatir el analfabetismo en Brasil: una investigación sobre las acciones del Programa Brasil Alfabetizado en municipios de Ceará

Este estudio tiene como objetivo analizar las características del Programa Brasil Alfabetizado (PBA) en municipios del estado de Ceará, que se unieron al programa. Así, fueron seleccionados por criterios de representatividad estadística, 15 condados que en el estado de Ceará se adhieren al programa. Los datos

DOI: http://dx.doi.org/10.1590/0034-76121514

Artigo recebido em 26 mar. 2013 e aceito em 13 fev. 2014.

Rev. Adm. Pública - Rio de Janeiro 48(3):641-666, maio/jun. 2014 
fueron recogidos a partir de los profesores del PBA en estos municipios, mediante la cumplimentación de un cuestionario estructurado, y analizados mediante la técnica de análisis de conglomerados. Con la separación de los municipios en distintos grupos, los resultados apuntan desviaciones de: criterios de selección de los alfabetizadores y su participación en cursos de formación; carga de trabajo, el material didáctico y los instructores del curso de formación de alfabetizadores; frecuencia de la coordinación de los cursos; duración del curso para alfabetización de los alumnos; la existencia de programas para personas con discapacidad visual y auditiva; y la evasión y la continuación de los estudios de los alumnos alfabetizados. Por lo tanto, estos resultados permitieron observar las siguientes necesidades en el fortalecimiento de PBA: la formación de sus profesores, la creación de programas para el mejoramiento de personas con discapacidad visual y auditiva; mejorar el acompañamiento de la coordinación de cursos y combate a los altos índices de deserción escolar de los estudiantes matriculados.

Palabras clave: política pública; analfabetismo; Programa Brasil Alfabetizado.

Public policies to fight illiteracy in Brazil: an investigation on the operation of the Literate Brazil Program in towns of Ceará

This study aims to analyze the characteristics of the Literate Brazil Program (PBA) in towns of the state of Ceará that joined the program. For this, we selected, by means of statistical criteria of representativeness, 15 towns in the state that adhered to the program. Data were collected from the literacy teachers in PBA at these towns, by filling out a structured questionnaire, and analyzed using the cluster analysis technique. Through the arrangement of towns into different groups, the findings pointed out divergences with regard to: criteria for selecting literacy teachers and their participation in training courses; workload, teaching material, and instructors of literacy teachers' training course; frequency of course coordination; length of the literacy course for students; existence of programs for visually and hearing-impaired people; and dropout and continuity of studies by literate students. Therefore, such results enabled us to observe the following needs for strengthening with regard to PBA: continued training of its literacy teachers; creation of programs for visually and hearing-impaired people; improvement of the monitoring of course coordinations; and fight against the high dropout rates on the part of enrolled students.

Keywords: public policy; illiteracy; Literate Brazil Program.

\section{Introdução}

O ano de 2012 finaliza a Década das Nações Unidas para a Alfabetização (2003-12), cujo lema foi "Alfabetização como Liberdade" (Unesco, 2003). No entanto, neste início de século XXI, o problema do analfabetismo ainda permanece como um dos grandes desafios para a sociedade mundial. Atualmente, é sabido que um terço da população do globo é composto de analfabetos, e nos países em desenvolvimento o analfabetismo chega a atingir mais da metade da população (Unesco, 2009). No Brasil, este é um problema que nasceu com o país e que o vem acompanhando ao longo dos seus mais de 500 anos de história.

Conforme apontam Pinto e colaboradores (2000), foram inúmeras as tentativas de erradicar o analfabetismo no país, como a Campanha de Educação de Adolescentes e Adultos 
de 1947; a Campanha Nacional de Erradicação do Analfabetismo de 1958; o Programa Nacional de Alfabetização, baseado no método Paulo Freire, de 1964; o Movimento Brasileiro de Alfabetização (Mobral) entre os anos de 1968 e 1978; a Fundação Nacional de Educação de Jovens e Adultos (Educar) de 1985; o Programa Nacional de Alfabetização e Cidadania (Pnac) de 1990; o Plano Decenal de Educação para Todos de 1993; e, no final do último século, o Programa de Alfabetização Solidária, de 1997. Assim, percebe-se que, em cada governo, foram promovidos esforços no sentido de combater o analfabetismo, que se mostra como um problema social crônico no Estado brasileiro.

Contudo, apesar dos esforços nacionais, o problema continua existindo e impedindo o pleno exercício da cidadania pela parcela da população que não sabe ler. Essa exclusão social é brutal, pois mantém o ciclo vicioso da pobreza e impede a evolução econômica do analfabeto que, segundo Freire (1990), é vítima de uma injustiça social que lhe nega o direito à alfabetização. Corroborando com essa assertiva, Teixeira (2012) afirma que o analfabetismo é um obstáculo para a construção de uma sociedade livre, justa e solidária, sendo a alfabetização um requisito para a própria existência de uma democracia. Tais ideias ganham força principalmente na sociedade contemporânea, onde o conhecimento se estabelece como "o maior gerador de riqueza" (Steiner, 2006:75).

Na última década, foi lançado pelo governo brasileiro o Programa Brasil Alfabetizado (PBA), voltado para a alfabetização de jovens, adultos e idosos, principalmente em municípios com taxas de analfabetismo superiores a $25 \%$, cuja quase totalidade, cerca de $90 \%$, encontrase localizada na região Nordeste do país. Dentre os estados da região Nordeste, o Ceará se destaca entre aqueles com maior taxa de analfabetismo: 17,19\%, segundo dados do MEC (2012).

Dessa forma, este estudo tem como objetivo analisar as características do Programa Brasil Alfabetizado (PBA) - em relação a currículo do alfabetizador, curso de formação de alfabetizadores, atuação da coordenação, curso de alfabetização e adesão/evasão dos alunos, em municípios do estado do Ceará que aderiram ao programa. Considerado uma importante ferramenta da política pública educacional atual que visa erradicar o analfabetismo do Brasil, o PBA se constitui como o mais recente esforço governamental na luta contra o analfabetismo. Assim, uma investigação que tenha como foco avaliar seu desenvolvimento em uma das regiões de maior índice de analfabetismo do país se mostra imperativa.

Para tanto, foram selecionados, mediante critérios estatísticos de representatividade, 15 municípios do estado do Ceará aderentes ao programa. Os dados foram coletados junto aos alfabetizadores do PBA destes municípios, mediante preenchimento de questionário estruturado, sendo coletados 329 questionários válidos, os quais foram organizados e analisados mediante técnica de análise de conglomerados, com o auxílio dos softwares Microsoft Excel (versão 2012) e IBM SPSS (versão 21), para a construção de tabelas e gráficos.

Ademais, espera-se que este estudo possa contribuir com uma maior compreensão das características de ação do PBA, sob a percepção dos alfabetizadores, produzindo mecanismos de avaliação do programa, bem como possibilitando a elaboração de recomendações que venham a melhorar o exercício do programa e seus resultados junto à população analfabeta. 


\section{Políticas públicas de alfabetização no mundo e no Brasil}

A alfabetização no mundo tem aumentado, visto que a transmissão do conhecimento depende quase sempre da escrita e, sem a habilidade de ler e escrever, a humanidade exclui-se da cultura e da aquisição de habilidades ou oportunidades. Portanto, a alfabetização pode colaborar para o atendimento das metas dos indivíduos, contribuindo de forma substancial para seu processo de inclusão social.

Conforme a Unesco (2008), o mundo conta com uma população de quase 800 milhões de jovens e adultos analfabetos, dos quais dois terços são mulheres. A difusão da alfabetização no Brasil ocorreu apenas no transcorrer do século XX, acompanhando a retardatária estruturação do sistema público de ensino. As primeiras políticas públicas nacionais destinadas à instrução dos jovens e adultos foram implementadas a partir de 1947, quando se estruturou o Serviço de Educação de Adultos do Ministério da Educação e teve início a Campanha de Educação de Adolescentes e Adultos.

O aumento da taxa de alfabetização de adultos no mundo, pessoas consideradas com mais de 15 anos, passou de $76 \%$ a 83,6\% nas duas últimas décadas, refletindo um considerável acréscimo, de tal forma que os países em desenvolvimento mostraram um expressivo aumento de $68 \%$ para $79 \%$. Porém, os avanços ainda não são suficientes para atender ao objetivo da educação para 2015 de reduzir à metade as taxas de analfabetismo (Unesco, 2009).

Segundo Faria (2003), a Organização das Nações Unidas (ONU) realizou, na década de 1990, um conjunto de conferências internacionais cujo foco foi a construção de um novo conceito de desenvolvimento. Entre essas reuniões, inclui-se a V Conferência Internacional de Educação de Adultos - V Confintea, realizada em Hamburgo, na Alemanha, em 1997. A Confintea, por sua vez, refletiu sobre o papel que a Educação de Jovens e Adultos (EJA) deveria desempenhar para atingir maiores níveis de igualdade e de justiça social, formulando, com isso, um amplo conceito de formação de pessoas jovens e adultas que contemple os processos de educação formais e não formais, bem como as transformações econômicas, a globalização dos mercados e também o aumento da pobreza.

Nesse contexto, para a Unesco (1999:23) a alfabetização é concebida como "conhecimento básico, necessário a todos num mundo em transformação; em sentido amplo, é um direito humano fundamental. Em toda a sociedade, a alfabetização é uma habilidade primordial em si mesma e um dos pilares para o desenvolvimento de outras habilidades". Dessa forma, a alfabetização teria como papel fundamental a promoção da participação do indivíduo em atividades sociais, econômicas, políticas e culturais, constituindo-se como elemento básico para uma educação continuada e permanente. Já Frago (1993:15) afirma, em sentido mais amplo, que o analfabeto é "aquele que não conhece ou não sabe nada sobre um tema determinado". Nesse sentido, analfabeto não é quem apenas não saiba ler e escrever, mas também aquele que seja incapaz de compreender ou redigir um texto determinado. 
A alfabetização é parte do direito à educação, além de propiciar o acesso a outros direitos. Para tal, vislumbra-se a necessidade de políticas públicas de alfabetização abrangentes, apoiadas por recursos adequados. Além disso, é necessário alcançar os líderes mundiais, visto que sem vontade política poucos avanços são alcançados. Na verdade, a prática da alfabetização é parte de um amplo debate sobre a educação com qualidade. Na acepção de Di Pierro (2008), embora o perfil e a atuação dos movimentos e organizações sociais tenham se modificado de forma substancial no final do século passado, o paradigma da educação popular ainda é a principal referência das práticas de formação para a cidadania com cunho democrático e defesa de direitos, particularmente aquelas promovidas por organizações da sociedade civil.

De acordo com a Unesco (2003), a visão da alfabetização como um direito humano deriva diretamente da Declaração Universal dos Direitos do Homem, que, em 1948, consagrou a educação como um direito básico. A avaliação dos avanços alcançados em todo o mundo no tocante à alfabetização é uma tarefa complexa e multifacetada. Sistemas de manutenção de registros, de coleta e análise de dados, de elaboração de comparações entre países e regiões e de interpretação dos resultados têm de ser construídos e mantidos, como instrumentos de apoio às políticas públicas de alfabetização no mundo.

Azevedo (2004) afirma que as políticas públicas podem ser entendidas como um dos mecanismos pelos quais o Estado age. Isso implica dizer que as políticas públicas são o Estado em ação, ou "a materialidade da intervenção do Estado". De acordo com Mello (1991:12),

a educação passa definitivamente a ocupar, juntamente com a política de ciência e tecnologia, lugar central e articulado na pauta das macropolíticas do Estado, como fator importante para a qualificação dos recursos humanos requeridos pelo novo padrão de desenvolvimento, no qual a produtividade e a qualidade dos bens e produtos são decisivos para a competitividade internacional.

Para Giron (2008), as políticas públicas são implementadas, reformuladas e desativadas segundo as diferentes formas, funções e opções ideológicas assumidas pelos dirigentes do Estado nos diferentes tempos históricos. Com relação às políticas educacionais, em especial, àquelas voltadas à alfabetização ao redor do mundo, o contexto não é distinto. O que se percebe é uma série de iniciativas que contribuem para uma base mais sólida em relação às ações de alfabetização hoje e no futuro.

No Brasil, por exemplo, a taxa de analfabetismo entre a população com 15 anos ou mais diminuiu quatro pontos percentuais entre 2000 e 2010, de 13,6\% para 9,6\%, segundo os Indicadores Sociais Municipais do Censo Demográfico de 2010. No caso da população com 15 anos ou mais, as maiores quedas se deram no Norte (de 16,3\% em 2000 para 11,2\% em 2010) e no Nordeste (de 26,2\% para 19,1\%), porém houve reduções também nas regiões Sul (de $7,7 \%$ para $5,1 \%$ ), Sudeste (de $8,1 \%$ para $5,4 \%$ ) e Centro-Oeste (de 10,8\% para 7,2\%). A tabela 1 apresenta uma evolução histórica do índice de analfabetismo no país. 
Tabela 1

Analfabetismo na faixa de 15 anos ou mais no Brasil, 1900-2010

\begin{tabular}{|cccc|}
\hline Ano & \multicolumn{1}{c}{ Total* } & Analfabeta* $^{*}$ & $\begin{array}{c}\text { Taxa de } \\
\text { analfabetismo }\end{array}$ \\
\hline 1900 & 9.728 & 6.348 & $65,25 \%$ \\
1920 & 17.564 & 11.409 & $64,96 \%$ \\
1940 & 23.648 & 13.629 & $57,63 \%$ \\
1940 & 30.188 & 15.272 & $50,59 \%$ \\
1960 & 40.233 & 15.964 & $39,68 \%$ \\
1970 & 53.633 & 18.100 & $33,75 \%$ \\
1980 & 74.600 & 19.356 & $25,95 \%$ \\
1991 & 94.891 & 18.682 & $19,69 \%$ \\
2000 & 119.533 & 16.295 & $13,63 \%$ \\
2010 & 144.824 & 13.941 & $9,63 \%$ \\
\hline
\end{tabular}

Fonte: IBGE (2010).

Nota: * valores em milhares.

Alguns exemplos sobre o foco do desenvolvimento de políticas públicas voltadas à alfabetização de jovens e adultos no mundo e no Brasil foram sintetizados no quadro 1.

\section{Quadro 1}

\section{Exemplos de políticas públicas de alfabetização de jovens e adultos no mundo}

\begin{tabular}{|c|l|}
\hline China & $\begin{array}{l}\text { Foco da política de alfabetização concentrado em áreas pobres, populações rurais, mulheres e } \\
\text { minorias étnicas. Entre } 1997 \text { e } 2012 \text {, conseguiu } 90 \text { milhões de novos adultos alfabetizados. }\end{array}$ \\
\hline Índia & $\begin{array}{l}\text { Foco na alfabetização funcional e ênfase na alfabetização feminina; inclusão de áreas com baixo grau } \\
\text { de alfabetização, especialmente a região norte do país. }\end{array}$ \\
\hline Marrocos & $\begin{array}{l}\text { Foco nos projetos locais de desenvolvimento, com a promoção de atividades geradoras de renda e } \\
\text { conscientização para aspectos de saúde, especialmente para as mulheres. }\end{array}$ \\
\hline Nigéria & $\begin{array}{l}\text { Foco na parceria com a sociedade civil, participação da comunidade e melhoria da qualidade de } \\
\text { oferta da alfabetização. }\end{array}$ \\
\hline Brasil & $\begin{array}{l}\text { Foco na educação básica continuada para quem participou do PBA; criação da Secretaria de Educação } \\
\text { Continuada, Alfabetização e Diversidade (Secad); programas de alfabetização mais longos; novas } \\
\text { ferramentas de monitoramento e avaliação; aumento dos investimentos pelos estados e municípios. }\end{array}$ \\
\hline
\end{tabular}

Fonte: Unesco (2009).

No contexto brasileiro, Mortatti (2010) esclarece que, a partir de 1930, com o processo de unificação em nível federal de iniciativas políticas em todas as esferas da vida social no 
Brasil, a educação e, de forma particular, a alfabetização passaram a integrar políticas e ações dos governos estaduais como áreas estratégicas para a promoção e sustentação do desejado desenvolvimento nacional.

Em consequência das transformações ocorridas na legislação da educação brasileira e do acúmulo de acordos produzidos em conferências nacionais e internacionais, a Educação de Jovens e Adultos foi colocada no centro do debate das políticas públicas. O que se impõe para os pesquisadores, educadores e gestores de políticas públicas, do campo popular, é a construção de processos de alfabetização que estabeleçam a leitura de mundo como condição à leitura da palavra (Faria, 2003). Neste contexto, Weisz (2002) assevera que as políticas públicas voltadas para os alunos na alfabetização inicial estão ainda dando os primeiros passos. Um dos fatores que contribuíram para isso foi a mudança no olhar da sociedade brasileira para a questão da educação. Finalmente se começa a compreender o papel econômico da educação no desenvolvimento do país e, com isso, ela começou a ser levada mais a sério.

Di Pierro (2008) ainda argumenta que a ampliação das exigências sociais de conhecimento, em paralelo ao alargamento do conceito de alfabetização, direcionou-se à educação de jovens e adultos com escolaridade reduzida e de baixa qualidade que, por causa da transição demográfica e dos insucessos dos sistemas de ensino, congregam um contingente extremamente numeroso. Vale ressaltar que, a partir de 2003, o governo brasileiro assumiu um novo discurso em prol da alfabetização de jovens e adultos, à qual consagrou maior investimento federal.

De fato, no Brasil, ao longo de aproximadamente 130 anos de história da alfabetização, pode-se constatar a centralidade atribuída pelas políticas públicas a um ou poucos aspectos específicos do processo de alfabetização, tendendo-se a reduzi-lo a aspectos neutros e meramente técnicos. Em virtude da multifacetação e complexidade do processo escolar no país, a história da alfabetização ainda se caracteriza como um complexo movimento, marcado pela recorrência discursiva da mudança, tendo como indicativo uma tensão constante entre rupturas e mudanças, diretamente relacionadas a disputas pela hegemonia de projetos educacionais e políticos e de um sentido moderno para a alfabetização (Mortatti, 2010). Nesse sentido, as políticas públicas de combate ao analfabetismo no Brasil precisam se reconfigurar para atender às novas demandas do cenário vigente da educação no país.

\section{O Programa Brasil Alfabetizado (PBA)}

Torna-se crescente a implementação de programas de educação de jovens e adultos, ocupando um cenário de destaque no sistema educacional brasileiro. Entender os processos de ensino e aprendizagem, assim como as políticas públicas de alfabetização de jovens e adultos, é vital para evidenciar o surgimento de melhores oportunidades de trabalho e melhoria da qualidade de vida para um contingente de pessoas que, a priori, pertenceria a um quadro de exclusão social. 
Ao final dos anos 1940, as primeiras políticas públicas nacionais de educação escolar para adultos foram implementadas, disseminando pelo território brasileiro campanhas de alfabetização. Já no início da década de 1960, movimentos de educação e cultura popular ligados a organizações sociais, à Igreja Católica e a governos desenvolveram experiências de alfabetização de adultos orientadas a conscientizar os participantes de seus direitos, analisar criticamente a realidade e nela intervir para transformar as estruturas sociais injustas (Di Pierro, 2005).

Conforme Di Pierro (2001), o engajamento dos municípios na atividade educacional, por sua vez, correlaciona-se a vários dispositivos da Constituição de 1988, que garantiu aos cidadãos o direito ao ensino fundamental público e gratuito em qualquer idade, responsabilizando a esfera pública por ofertá-la, vinculando parcela da receita de impostos a despesas com a educação e promovendo uma descentralização dos tributos em favor dos municípios para a ampliação de sua capacidade de investimento.

Nos parâmetros da legislação, o papel do governo federal é, principalmente, de orientador e indutor de políticas públicas voltadas à alfabetização, visando a corrigir desigualdades com garantia de um padrão mínimo de qualidade de ensino. Durante duas gestões do governo federal, 1995 a 2002, a diretriz do Ministério da Educação (MEC) foi focalizada no ensino fundamental para crianças e adolescentes. A estrutura de suporte político-pedagógico para a EJA, neste período, era reduzida (MEC, 2009).

Dentre as ações executadas na esfera municipal, o Ministério da Educação assumiu a responsabilidade quanto à alfabetização de adultos e vem realizando, desde 2003, o Programa Brasil Alfabetizado (PBA), voltado para a alfabetização de jovens, adultos e idosos. O programa é uma porta de acesso à cidadania e o despertar do interesse pela elevação da escolaridade. Segundo o MEC (2012), o Programa Brasil Alfabetizado (PBA) é desenvolvido em todo o território nacional, presente em mais de 3.500 municípios, e contemplando prioritariamente 1.928 municípios que apresentam taxa de analfabetismo igual ou superior a $25 \%$. Desse montante, 90\% localizam-se na região Nordeste. Esses municípios recebem apoio técnico na implementação das ações do programa, objetivando garantir a continuidade dos estudos aos alfabetizandos.

Por meio das resoluções específicas publicadas no Diário Oficial da União, os estados, os municípios e o Distrito Federal podem aderir ao PBA. De acordo com o art. $2^{\circ}$ da resolução CD/FNDE no 32, de 1ำ de julho de 2011, são objetivos do Programa Brasil Alfabetizado: 1. Contribuir para superar o analfabetismo no Brasil, universalizando a alfabetização de jovens, adultos e idosos e a progressiva continuidade dos estudos em níveis mais elevados, promovendo o acesso à educação como direito de todos, em qualquer momento da vida, por meio da responsabilidade solidária entre a União, os estados, o Distrito Federal e os municípios; 2. Colaborar com a universalização do ensino fundamental, apoiando as ações de alfabetização de jovens, adultos e idosos realizadas pelos estados, Distrito Federal e municípios, seja por meio da transferência direta de recursos financeiros suplementares aos que aderirem ao Programa, seja pelo pagamento de bolsas a voluntários que nele atuam.

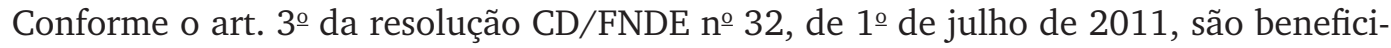
ários do PBA: 1. Jovens com 15 anos ou mais, adultos e idosos não alfabetizados, doravante denominados alfabetizandos; 2. Voluntários alfabetizadores; 3. Voluntários tradutores-intér- 
pretes da Língua Brasileira de Sinais (Libras), que atuarão em turmas com pessoas com surdez ou com deficiência auditiva, usuárias de Libras; e 4. Voluntários coordenadores de turmas.

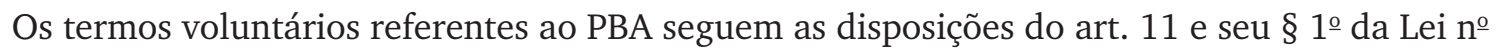
10.880, de 19 de junho de 2004, e do art. 1ํ da Lei no 9.608 , de 18 de fevereiro de 1998, não consistindo em vínculo empregatício, pois estabelecem que:

Art. 11. As atividades desenvolvidas pelos alfabetizadores no âmbito do Programa Brasil Alfabetizado são consideradas de natureza voluntária (...)

$\S 1$ 으 alfabetizador poderá receber uma bolsa para atualização e custeio das despesas realizadas no desempenho de suas atividades no Programa. (Brasil, 2004)

Segundo Rummert e Ventura (2007), o PBA foi implementado em 2003 para "erradicar" o analfabetismo no Brasil, tendo por finalidade "capacitar alfabetizadores e alfabetizar cidadãos com 15 anos ou mais que não tiveram oportunidade ou foram excluídos da escola antes de aprender a ler e escrever". Como principal ação estratégica, o PBA apoia e financia projetos de alfabetização de jovens, adultos e idosos apresentados pelos estados, municípios e Distrito Federal. A Secretaria de Educação Continuada, Alfabetização, Diversidade e Inclusão, do Ministério da Educação (Secadi/MEC,), é o órgão responsável pela coordenação e pelo gerenciamento do Programa em todo o país.

Conforme a Unesco (2008), em 2004 e 2005, a Universidade Federal do Estado do Rio de Janeiro, no âmbito de um convênio firmado entre a Unesco e a Secadi/MEC, realizou uma pesquisa abrangendo instituições governamentais e não governamentais em 10 municípios de seis estados (Alagoas, Goiás, Mato Grosso do Sul, Paraíba, Piauí e Rio de Janeiro), nos quais o PBA se desenvolvia concomitantemente. O estudo constatou que a maioria dos alfabetizandos do PBA era mulheres (70\%) e pessoas com mais de 30 anos, sendo muito rara a presença de jovens, e que a maioria das alfabetizadoras era mulheres (80\%) na faixa etária de 25 a 34 anos, formadas no ensino médio ou Normal (80\%).

O MEC, através do Fundo Nacional de Desenvolvimento da Educação (FNDE), disponibiliza os recursos para a execução do programa. Os voluntários alfabetizadores, os coordenadores de turmas e os intérpretes de Libras recebem uma bolsa, como forma de retribuição pelo trabalho prestado. Além do pagamento de bolsas, o MEC/FNDE repassa recursos financeiros aos estados e municípios, por meio de transferência automática, para financiamento das seguintes ações: formação de alfabetizadores, aquisição de gêneros alimentícios para a merenda e, também, de materiais escolares, pedagógicos, didáticos e literários, e de apoio ao professor em geral.

A responsabilidade constitucional pelo financiamento da EJA é dos estados e municípios, visto que, de acordo com a legislação, o papel do governo federal é, principalmente, de orientador e indutor de políticas, visando a corrigir desigualdades com garantia de um padrão mínimo de qualidade de ensino. Para se avaliar gastos de estados e municípios com EJA, é necessário que se faça uma série de estimativas, uma vez que o Brasil não possui, ainda, um sistema adequado de acompanhamento dos gastos educacionais dos entes federados (MEC, 2009).

Os municípios e os estados são considerados os executores do PBA, devendo realizar as ações destinadas à consecução dos objetivos do programa. Cabe ao ente executor indicar 
o gestor do programa em sua esfera de atuação, bem como localizar e identificar os jovens, adultos e idosos não alfabetizados possíveis de serem beneficiados pelo programa. O município deve ainda realizar ações que permitam na prática a implementação do programa, tais como: a seleção dos alfabetizadores, a execução do plano de formação inicial e continuada, a manutenção mensal atualizada das informações cadastrais das instituições, alfabetizadores e alunos e a realização do controle de frequência (Brasil, 2011).

\section{Metodologia da pesquisa}

Para consecução do objetivo proposto para este estudo, que consiste em analisar as características do Programa Brasil Alfabetizado (PBA) em municípios do estado do Ceará que aderiram ao programa, fez-se uso de abordagem quantitativa e de cunho descritivo, cujo potencial, conforme Minayo e Sanches (1993), reside na possibilidade de se estabelecer inferência estatística dos achados.

Devido à extensão territorial do estado do Ceará e ao limite de pesquisadores disponíveis à realização do trabalho, torna-se inviável a realização de uma auditoria nos 184 municípios desse estado. Necessário se faz, então, retirar da população uma amostra, que passará a representá-la. Para a definição dessa amostra, foi realizada a estratificação dos 167 municípios aderentes ao Programa Brasil Alfabetizado no ciclo 2010 levando em consideração o número de alfabetizadores e coordenadores de turmas, que somaram 6.851 bolsistas, gerando, assim, uma amostra probabilística estratificada proporcional, que assegura que todas as características da população estejam presentes e na mesma proporção (Freitas et al., 2000). Assim, foram selecionados municípios que, em conjunto, representam toda a população de municípios do estado do Ceará. A tabela 2 apresenta informações relativas ao analfabetismo e PBA nos 15 municípios selecionados para a pesquisa.

Tabela 2

Dados do analfabetismo e PBA nos municípios pesquisados

\begin{tabular}{|lccccc|}
\hline Municípios & $\begin{array}{c}\text { População } \\
\text { Total* }\end{array}$ & $\begin{array}{c}\text { Qtde. de } \\
\text { Analfabetos* }\end{array}$ & $\begin{array}{c}\text { Índice de } \\
\text { Analfabetismo }\end{array}$ & $\begin{array}{c}\text { № de Bolsistas } \\
\text { no PBA }\end{array}$ & $\begin{array}{c}\text { Turmas } \\
\text { Concluídas }\end{array}$ \\
\hline Acopiara & 38.439 & 12.680 & $32,99 \%$ & 141 & 130 \\
Araripe & 14.214 & 4.767 & $33,54 \%$ & 38 & 34 \\
Brejo Santo & 33.637 & 7.641 & $22,72 \%$ & 139 & 125 \\
Capistrano & 12.355 & 3.413 & $27,62 \%$ & 92 & 83 \\
Caucaia & 236.661 & 30.499 & $12,89 \%$ & 127 & 103 \\
Guaraciaba do Norte & 26.263 & 7.466 & $28,43 \%$ & 74 & 65 \\
Icapuí & 13.846 & 3.583 & $25,88 \%$ & 161 & 111 \\
Icó & 48.234 & 15.838 & $32,84 \%$ & 235 & 215 \\
Independência & 19.134 & 5.537 & $28,94 \%$ & 203 & 187 \\
\hline
\end{tabular}




\begin{tabular}{|lccccc|}
\hline Municípios & $\begin{array}{c}\text { População } \\
\text { Total* }\end{array}$ & $\begin{array}{c}\text { Qtde. de } \\
\text { Analfabetos* }\end{array}$ & $\begin{array}{c}\text { Índice de } \\
\text { Analfabetismo }\end{array}$ & $\begin{array}{c}\text { № de Bolsistas } \\
\text { no PBA }\end{array}$ & $\begin{array}{c}\text { Turmas } \\
\text { Concluídas }\end{array}$ \\
\hline Irauçuba & 15426 & 4.321 & $28,01 \%$ & 88 & 77 \\
Itapipoca & 81465 & 18.423 & $22,61 \%$ & 637 & 572 \\
Jaguaribe & 25582 & 6.540 & $25,56 \%$ & 66 & 58 \\
Mauriti & 31.645 & 9.328 & $29,48 \%$ & 98 & 90 \\
Tauá & 40.981 & 11.249 & $27,45 \%$ & 246 & 215 \\
Tururu & 10.416 & 2.916 & $28,00 \%$ & 76 & 66 \\
\hline
\end{tabular}

Fonte: Ministério da Educação (2010).

Nota: * população de 15 anos ou mais.

O município de Fortaleza foi excluído da amostra, devido a suas características singulares, não passíveis de comparação ou generalização em relação aos demais. A quantidade de questionários foi estabelecida com aplicação de fórmula para cálculo amostral, chegando-se ao número de 370 questionários para os alfabetizadores dos municípios da amostra, sendo possível aplicar 329, conforme quadro 2, mantendo o nível de confiança de 95\% e o erro amostral em $5 \%$.

Quadro 2

Distribuição amostral da pesquisa

\begin{tabular}{|lccc|}
\hline Município & $\begin{array}{c}\text { Questionários } \\
\text { Programados }\end{array}$ & $\begin{array}{c}\text { Questionários } \\
\text { Preenchidos }\end{array}$ & Diferença \\
\hline Acopiara (ACO) & 13 & 15 & 2 \\
Araripe (ARA) & 13 & 15 & 2 \\
Brejo Santo (BRE) & 16 & 18 & 2 \\
Capistrano (CAP) & 15 & 18 & 3 \\
Caucaia (CAU) & 19 & 22 & 3 \\
Guaraciaba do Norte (GUA) & 15 & 15 & 0 \\
Icapuí (ICA) & 17 & 18 & 1 \\
Icó (ICO) & 33 & 25 & $(8)$ \\
Independência (IND) & 38 & 26 & 2 \\
Irauçuba (IRA) & 38 & 40 & $(34)$ \\
Itapipoca (ITA) & 80 & 46 & 2 \\
Jaguaribe (JAG) & 18 & 20 & 0 \\
Mauriti (MAU) & 15 & 15 & $(4)$ \\
Tauá (TAU) & 25 & 21 & 0 \\
Tururu (TUR) & 15 & 15 & $(41)$ \\
TOTAL & 370 & 329 & \\
\hline
\end{tabular}

Fonte: Dados da pesquisa. 
No que diz respeito ao instrumento de coleta de dados utilizado, esse questionário foi estruturado com 19 questões fechadas e de múltipla escolha, distribuídas em cinco áreas temáticas, sendo elas: currículo do alfabetizador (experiências anteriores, tipo de seleção, formações); cursos de formação de alfabetizadores (participação em cursos, conteúdos, pontos fracos); atuação da coordenação (acompanhamento dos alfabetizadores, frequência de visitas, solução de problemas); curso de alfabetização do PBA (duração, avaliação, programas especiais, continuidade nos estudos); adesão/evasão dos alunos (níveis de adesão/evasão, causas).

Para o tratamento dos dados coletados por meio desses questionários, utilizou-se a técnica de análise de conglomerados (cluster analysis), definida por Malhotra (2011:536) como "uma técnica usada para classificar objetos ou casos em grupos relativamente homogêneos chamados conglomerados. Os objetos em cada conglomerado tendem a ser semelhantes entre si, mas diferentes de objetos em outros conglomerados". Conforme Fávero e colaboradores (2009), sua utilização se destaca em face das demais técnicas estatísticas principalmente em estudos de cunho exploratório, sem hipóteses definidas a serem testadas, já que o agrupamento e a redução de um conjunto maior de observações em poucos grupos permitem uma análise ampliada e consistente dos dados coletados. Assim, o intuito de sua utilização consistiu na classificação dos municípios a partir das características comuns no que diz respeito aos aspectos do PBA, possibilitando a análise dessas características.

Vale ressaltar que, por ser geralmente aplicada apenas em amostras populacionais, a análise de conglomerados possui limitações quanto à inferência que pode ser feita dos grupos observados na amostra para a população geral (Corrar, Paulo e Dias Filho, 2009). Contudo, como este estudo se utilizou de critérios estatísticos para a estratificação da amostra e seleção dos municípios integrantes da pesquisa, essa limitação não é percebida, sendo os resultados atingidos representativos da população.

Ademais, para a organização e análise dos dados oriundos dos questionários, bem como construção das tabelas e gráficos que suportam esta análise quantitativa, foram utilizados os softwares Microsoft Excel (versão 2012) e IBM SPSS (versão 21).

\section{Apresentação e análise dos resultados}

Tendo em vista analisar as características de diversos municípios cearenses, no que diz respeito ao Programa Brasil Alfabetizado, os resultados dos questionários aplicados junto aos alfabetizadores do PBA foram agrupados por município, sendo calculadas as médias de respostas para cada uma das questões por município. Dessa forma, não houve necessidade de padronização dos dados, já que todas as variáveis se encontram no mesmo formato e escala numérica. A aplicação da técnica de conglomerados foi feita separadamente em cada um dos aspectos de avaliação que compunham o questionário utilizado, sendo eles: currículo do alfabetizador, 
curso de formação de alfabetizadores, atuação da coordenação, curso de alfabetização do PBA e, por fim, adesão/evasão dos alunos.

\subsection{Currículo dos alfabetizadores}

Devido às suas vantagens, optou-se pela utilização do critério hierárquico de agrupamento vizinho mais distante, baseado na distância máxima entre os casos dentro de cada grupo. Sua vantagem, conforme apontam Corrar, Paulo e Dias Filho (2009), está em eliminar o problema da cadeia ou corrente prolongada, presente quando os objetos estão pobremente estruturados, formando longas cadeias com todos os indivíduos, o que resulta em um único grupo. Assim, sua utilização aumenta as chances de se obterem grupos mais equilibrados e menos dissimilares. Os resultados desta primeira solução são apresentados na tabela 3, que traz as informações referentes a essa primeira etapa de análise estatística.

\section{Tabela 3}

Tabela de aglomeração dos municípios (currículo dos alfabetizadores)

\begin{tabular}{|c|c|c|c|c|c|c|}
\hline \multicolumn{7}{|c|}{ Agglomeration Schedule } \\
\hline \multirow[b]{2}{*}{ Stage } & \multicolumn{2}{|c|}{ Cluster Combined } & \multirow[b]{2}{*}{ Coefficients } & \multicolumn{2}{|c|}{ Stage Cluster First Appears } & \multirow[t]{2}{*}{ Next Stage } \\
\hline & Cluster 1 & Cluster 2 & & Cluster 1 & Cluster 2 & \\
\hline 1 & 4 & 12 & 019 & 0 & 0 & 2 \\
\hline 2 & 4 & 5 & , 181 & 1 & 0 & 7 \\
\hline 3 & 6 & 15 &, 244 & 0 & 0 & 10 \\
\hline 4 & 2 & 3 &, 313 & 0 & 0 & 6 \\
\hline 5 & 1 & 11 &, 371 & 0 & 0 & 10 \\
\hline 6 & 2 & 13 &, 427 & 4 & 0 & 8 \\
\hline 7 & 4 & 9 & ,497 & 2 & 0 & 12 \\
\hline 8 & 2 & 8 &, 757 & 6 & 0 & 11 \\
\hline 9 & 10 & 14 & 813 & 0 & 0 & 13 \\
\hline 10 & 1 & 6 & 817 & 5 & 3 & 11 \\
\hline 11 & 1 & 2 & 1,560 & 10 & 8 & 14 \\
\hline 12 & 4 & 7 & 1,771 & 7 & 0 & 13 \\
\hline 13 & 4 & 10 & 2,220 & 12 & 9 & 14 \\
\hline 14 & 1 & 4 & 3,578 & 11 & 13 & 0 \\
\hline
\end{tabular}

Fonte: Dados da pesquisa. 
Na primeira coluna (stage), são numeradas cada uma das etapas de agrupamento dos municípios. Por exemplo, na etapa 1, o município 4 (Capistrano) e o 12 (Jaguaribe) são agrupados. Já na etapa 2, o município 4 (Capistrano) é agrupado ao município 5 (Caucaia). Assim, nessa segunda etapa, caso a análise se encerrasse nesse ponto, teríamos um grupo formado por três municípios (Capistrano, Jaguaribe e Caucaia) e mais 12 grupos, cada um formado pelos demais municípios da amostra.

Para identificar qual resultado traria a quantidade de grupos mais significativa, observam-se os valores do coeficiente de aglomeração (coefficients). Em cada etapa, é calculado um valor para os agrupamentos formados — na etapa 1 , foi de 0,19 ; na etapa $2,0,181$, e assim por diante, sendo esse valor acumulado ao longo de todas as etapas. Assim, a escolha pela quantidade de grupos se dá mediante aplicação de um critério de parada simples, que considera os valores dos coeficientes entre as etapas, identificando momentos de elevação súbita. Percebe-se que da etapa 13 para a etapa 14 houve o maior aumento deste coeficiente $(2,220$ para 3,578). Assim, a parada é indicada no estágio anterior a esse aumento (etapa 13), onde os municípios da amostra haviam se agrupado em dois grupos, sendo eles:

Grupo 1 (oito municípios): Acopiara, Araripe, Brejo Santo, Guaraciaba do Norte, Icó, Itapipoca, Mauriti, Tururu.

Grupo 2 (sete municípios): Capistrano, Caucaia, Icapuí, Independência, Irauçuba, Jaguaribe, Tauá.

Interpretando os dois grupos encontrados, observa-se que a solução bipartida, os seja, de dois grupos, contempla razoavelmente as diferenças entre os grupos, tendo em vista as distâncias entre os dois grupos. Essa distância pode ser observada no gráfico chamado dendrograma, apresentado na figura 1, onde se pode verificar que o Grupo 1, na parte inferior do gráfico, teve a sua interação com uma distância reescalonada de 11, enquanto o Grupo 2 teve uma distância de 16. Essa distância reescalonada nada mais é do que uma medida utilizada para comparar as características gerais dos grupos formados. Desse modo, como os valores dessa distância, apresentados na escala no topo do gráfico, não são iguais ou seguidos, podese considerar que os grupos não são semelhantes entre si.

Uma análise das médias das respostas em cada um dos grupos indica que as diferenças entre eles estão relacionadas principalmente com os métodos de seleção pelos quais passaram os alfabetizadores do programa, sendo os alfabetizadores dos municípios pertencentes ao Grupo 1 escolhidos principalmente por meio de entrevista $(55,64 \%)$ e análise de currículo (48,60\%), enquanto os dos Grupo 2 foram por provas $(38,72 \%)$ e indicação $(49,26 \%)$. Além disso, percebe-se uma diferença na participação dos alfabetizadores em cursos de formação, mesmo após iniciadas as aulas no PBA, de forma que os alfabetizadores do Grupo 1 apresentaram uma média maior de participação do que os do Grupo 2 (90,41\% e 68,96\%, respectivamente). 
Figura 1

Dendrograma (currículo dos alfabetizadores)

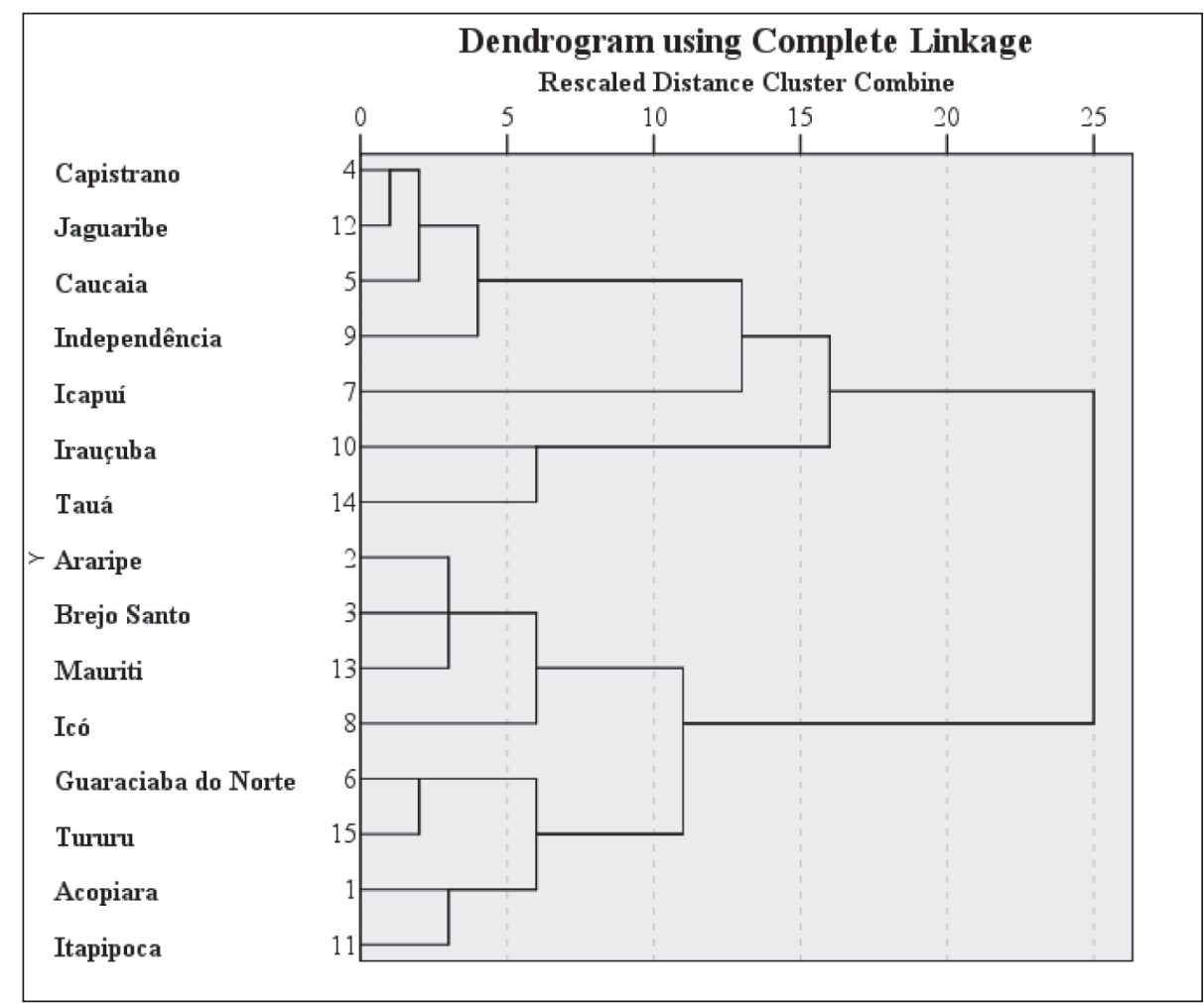

Fonte: Dados da pesquisa.

\subsection{Curso de formação dos alfabetizadores}

Nesta segunda aplicação da técnica de conglomerados, considerando as variáveis relativas à formação dos alfabetizadores, utilizou-se o mesmo critério hierárquico de agrupamento vizinho mais distante. Os resultados desta análise são apresentados na tabela 4.

Esta segunda análise agruparia as observações em dois grupos, sendo eles:

Grupo 1 (três municípios): Acopiara, Araripe, Icó.

Grupo 2 (12 municípios): Brejo Santo, Capistrano, Caucaia, Guaraciaba do Norte, Icapuí, Independência, Irauçuba, Itapipoca, Jaguaribe, Mauriti, Tauá, Tururu.

A escolha pela quantidade de dois grupos se deu mediante o mesmo critério da etapa anterior. Nesta fase, novamente da etapa 13 para a etapa 14 houve o maior aumento do coeficiente de aglomeração $(0,187$ para 0,338). Assim, a parada é indicada no estágio anterior a este aumento (etapa 13), onde a solução é de dois grupos. Na figura 2 é possível observar a distância escalonada nos dois grupos que, nessa etapa de análise, foi bastante próxima. 
Tabela 4

Tabela de aglomeração dos municípios (curso de formação dos alfabetizadores)

Agglomeration Schedule

\begin{tabular}{|c|c|c|c|c|c|c|}
\hline \multirow[b]{2}{*}{ Stage } & \multicolumn{2}{|c|}{ Cluster Combined } & \multirow[b]{2}{*}{ Coefficients } & \multicolumn{2}{|c|}{ Stage Cluster First Appears } & \multirow[t]{2}{*}{ Next Stage } \\
\hline & Cluster 1 & Cluster 2 & & Cluster 1 & Cluster 2 & \\
\hline 1 & 4 & 10 & ,009 & 0 & 0 & 5 \\
\hline 2 & 11 & 13 & ,015 & 0 & 0 & 6 \\
\hline 3 & 5 & 12 & ,020 & 0 & 0 & 5 \\
\hline 4 & 9 & 15 &, 021 & 0 & 0 & 8 \\
\hline 5 & 4 & 5 & ,039 & 1 & 3 & 11 \\
\hline 6 & 6 & 11 &, 043 & 0 & 2 & 10 \\
\hline 7 & 3 & 14 & ,043 & 0 & 0 & 8 \\
\hline 8 & 3 & 9 & ,065 & 7 & 4 & 11 \\
\hline 9 & 1 & 8 & ,072 & 0 & 0 & 13 \\
\hline 10 & 6 & 7 & 095 & 6 & 0 & 12 \\
\hline 11 & 3 & 4 & 128 & 8 & 5 & 12 \\
\hline 12 & 3 & 6 & 178 & 11 & 10 & 14 \\
\hline 13 & 1 & 2 & 187 & 9 & 0 & 14 \\
\hline 14 & 1 & 3 & ,338 & 13 & 12 & 0 \\
\hline
\end{tabular}

Fonte: Dados da pesquisa.

Figura 2

Dendrograma (curso de formação dos alfabetizadores)

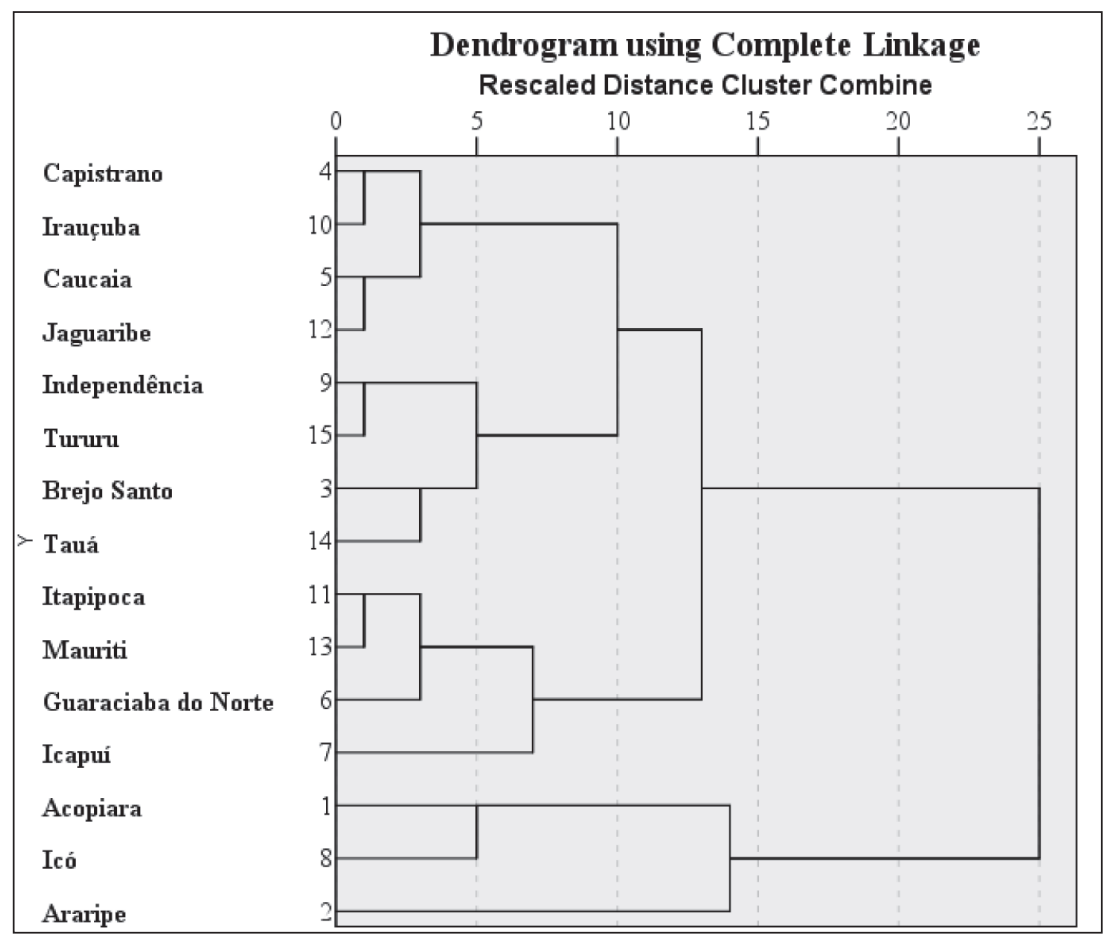

Fonte: Dados da pesquisa. 
As diferenças entre os grupos são observadas especificamente nas variáveis relativas à percepção dos alfabetizadores quanto a melhorias no curso de formação. Para os alfabetizadores dos municípios que compõem o Grupo 1, essas melhorias devem envolver principalmente a carga horária do curso (48,44\%), enquanto os alfabetizadores do Grupo 2 apontaram a necessidade de melhorias no material didático $(67,51 \%)$ e nos instrutores $(8,75 \%)$.

\subsection{Atuação da coordenação dos cursos}

Para a terceira aplicação da técnica de conglomerados, foram utilizadas variáveis relacionadas com a atuação dos coordenadores dos cursos de alfabetização do PBA junto aos alfabetizadores. Utilizando-se o critério hierárquico de agrupamento vizinho mais distante, obtiveram-se os seguintes resultados, apresentados na Tabela 5.

\section{Tabela 5}

Tabela de aglomeração dos municípios (atuação da coordenação dos cursos)

\begin{tabular}{|c|c|c|c|c|c|c|}
\hline \multirow[b]{3}{*}{ Stage } & \multicolumn{5}{|c|}{ Agglomeration Schedule } & \multirow{3}{*}{ Next Stage } \\
\hline & \multicolumn{2}{|c|}{ Cluster Combined } & \multirow[b]{2}{*}{ Coefficients } & \multicolumn{2}{|c|}{ Stage Cluster First Appears } & \\
\hline & Cluster 1 & Cluster 2 & & Cluster 1 & Cluster 2 & \\
\hline 1 & 11 & 15 & ,018 & 0 & 0 & 4 \\
\hline 2 & 8 & 10 &, 026 & 0 & 0 & 10 \\
\hline 3 & 6 & 9 & ,032 & 0 & 0 & 5 \\
\hline 4 & 11 & 14 &, 057 & 1 & 0 & 10 \\
\hline 5 & 1 & 6 & ,062 & 0 & 3 & 8 \\
\hline 6 & 2 & 4 & ,092 & 0 & 0 & 11 \\
\hline 7 & 3 & 5 &, 100 & 0 & 0 & 9 \\
\hline 8 & 1 & 13 &, 138 & 5 & 0 & 13 \\
\hline 9 & 3 & 7 & 166 & 7 & 0 & 11 \\
\hline 10 & 8 & 11 & ,219 & 2 & 4 & 14 \\
\hline 11 & 2 & 3 &, 340 & 6 & 9 & 12 \\
\hline 12 & 2 & 12 &, 404 & 11 & 0 & 13 \\
\hline 13 & 1 & 2 & ,985 & 8 & 12 & 14 \\
\hline 14 & 1 & 8 & 1,791 & 13 & 10 & 0 \\
\hline
\end{tabular}

Fonte: Dados da pesquisa.

Nesta terceira etapa de análise, os municípios foram, novamente, agrupados em dois grupos, já que da fase 13 para a fase 14 houve o maior aumento do coeficiente de aglomeração $(0,985$ para 1,791$)$, sendo eles:

Grupo 1 (10 municípios): Acopiara, Araripe, Brejo Santo, Capistrano, Caucaia, Guaraciaba do Norte, Icapuí, Independência, Jaguaribe, Mauriti.

Grupo 2 (cinco municípios): Icó, Irauçuba, Itapipoca, Tauá, Tururu. 
Na figura 3 é possível observar a distância escalonada nos dois grupos que, nessa etapa de análise, ficou próxima a 15 para o Grupo 1 e, para o Grupo 2, foi de três, evidenciando um resultado bastante satisfatório para essa separação dos municípios em dois grupos.

Figura 3

Dendrograma (atuação da coordenação dos cursos)

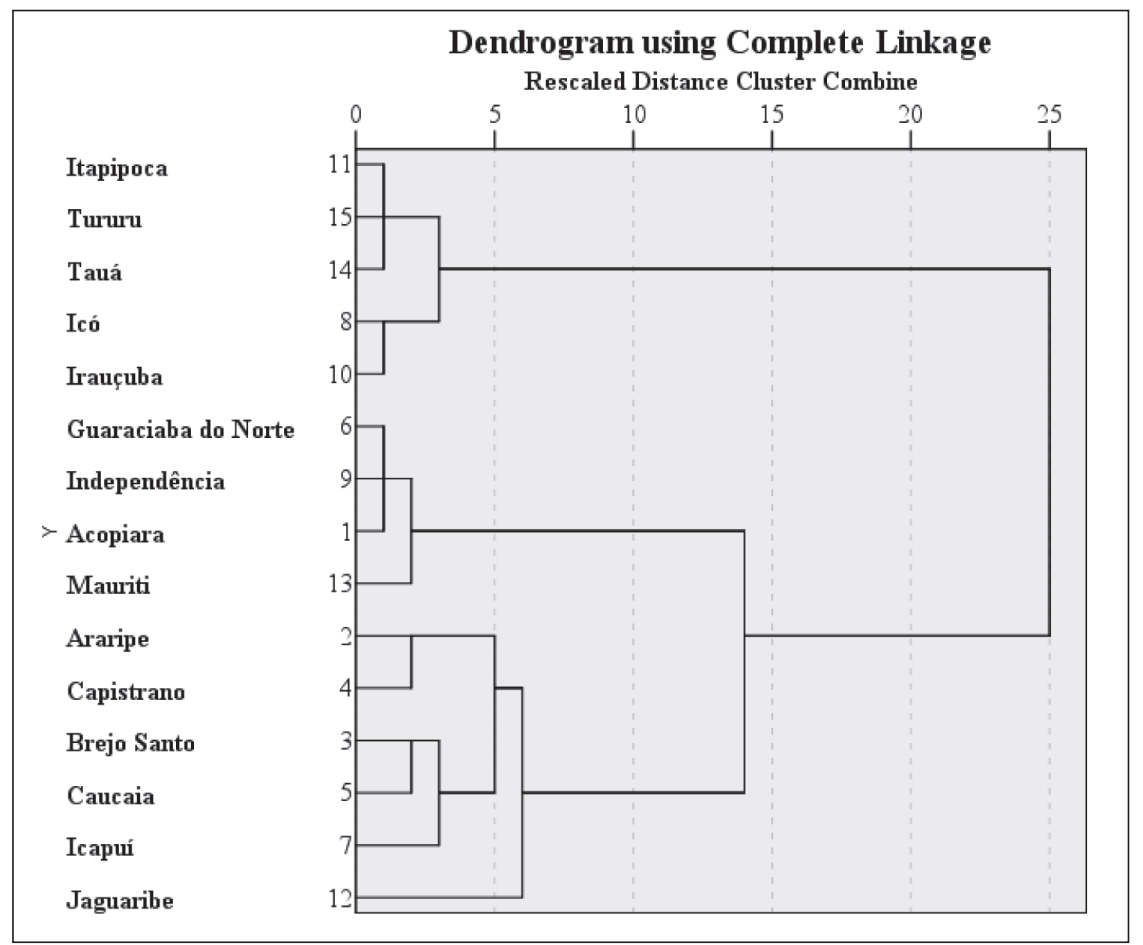

Fonte: Dados da pesquisa.

Nesta fase da análise, as diferenças entre os dois grupos se concentraram na frequência das visitas da coordenação às turmas de alfabetização do PBA. Os alfabetizadores dos municípios do Grupo 2 apontaram uma média de visitas semanais maior (73\%), enquanto no Grupo 1 a média maior foi a de visitas mensais $(58,46 \%)$.

\subsection{Curso de alfabetização do PBA}

Na quarta etapa de aplicação da análise de conglomerados, as variáveis utilizadas foram as referentes à estrutura e ao desenvolvimento do curso de alfabetização desenvolvido pelo PBA. Por meio do mesmo critério hierárquico de agrupamento vizinho mais distante, obtiveram-se os seguintes resultados, apresentados na tabela 6 . 
Tabela 6

Tabela de aglomeração dos municípios (curso de alfabetização do PBA)

\begin{tabular}{|c|c|c|c|c|c|c|}
\hline \multicolumn{7}{|c|}{ Agglomeration Schedule } \\
\hline \multirow[b]{2}{*}{ Stage } & \multicolumn{2}{|c|}{ Cluster Combined } & \multirow[b]{2}{*}{ Coefficients } & \multicolumn{2}{|c|}{ Stage Cluster First Appears } & \multirow[t]{2}{*}{ Next Stage } \\
\hline & Cluster 1 & Cluster 2 & & Cluster 1 & Cluster 2 & \\
\hline 1 & 6 & 10 & ,079 & 0 & 0 & 8 \\
\hline 2 & 9 & 14 & ,086 & 0 & 0 & 6 \\
\hline 3 & 5 & 12 & 104 & 0 & 0 & 9 \\
\hline 4 & 7 & 13 &, 179 & 0 & 0 & 8 \\
\hline 5 & 1 & 2 &, 191 & 0 & 0 & 9 \\
\hline 6 & 4 & 9 & 199 & 0 & 2 & 11 \\
\hline 7 & 3 & 8 &, 222 & 0 & 0 & 10 \\
\hline 8 & 6 & 7 & 265 & 1 & 4 & 11 \\
\hline 9 & 1 & 5 &, 357 & 5 & 3 & 13 \\
\hline 10 & 3 & 11 &, 427 & 7 & 0 & 13 \\
\hline 11 & 4 & 6 & 840 & 6 & 8 & 12 \\
\hline 12 & 4 & 15 & 1,052 & 11 & 0 & 14 \\
\hline 13 & 1 & 3 & 1,147 & 9 & 10 & 14 \\
\hline 14 & 1 & 4 & 1,958 & 13 & 12 & 0 \\
\hline
\end{tabular}

Fonte: Dados da pesquisa.

Nesta quarta etapa de análise, os municípios foram também agrupados em dois grupos distintos. Observa-se que da fase 13 para a fase 14 se tem o maior aumento do coeficiente de aglomeração (de 1,147 para 1,958), ficando os grupos estruturados da seguinte forma:

Grupo 1 (sete municípios): Acopiara, Araripe, Brejo Santo, Caucaia, Icó, Itapipoca, Jaguaribe.

Grupo 2 (oito municípios): Capistrano, Guaraciaba do Norte, Icapuí, Independência, Irauçuba, Mauriti, Tauá, Tururu.

A figura 4 apresenta a distância escalonada nos dois grupos. Levando-se em consideração apenas as variáveis relativas ao curso de alfabetização do PBA, essa distância não foi muito representativa da diferença dos grupos, ficando o Grupo 1 próximo a 15 e o Grupo 2 com pouco mais de 13 .

As diferenças entre os grupos nesta análise, considerando apenas as variáveis diretamente relacionadas com aspectos da estrutura e do desenvolvimento do curso de alfabetização do PBA, se concentraram na duração do curso e na existência de programas de auxílio para portadores de deficiência visual. Para os alfabetizadores atuantes nos municípios que compunham o Grupo 1, a duração atual dos cursos seria suficiente para garantir a alfabetização dos alunos $(58,41 \%)$, além de apontarem a existência de programas especiais para pessoas com problemas de visão (73,50\%). Em contrapartida, os alfabetizadores dos municípios 
alocados no Grupo 2 não perceberam como satisfatória a duração do curso (70,38\%), além de apontarem para a inexistência de programas especiais de alfabetização para pessoas com problemas de visão $(58,84 \%)$.

\section{Figura 4}

Dendrograma (curso de alfabetização do PBA)

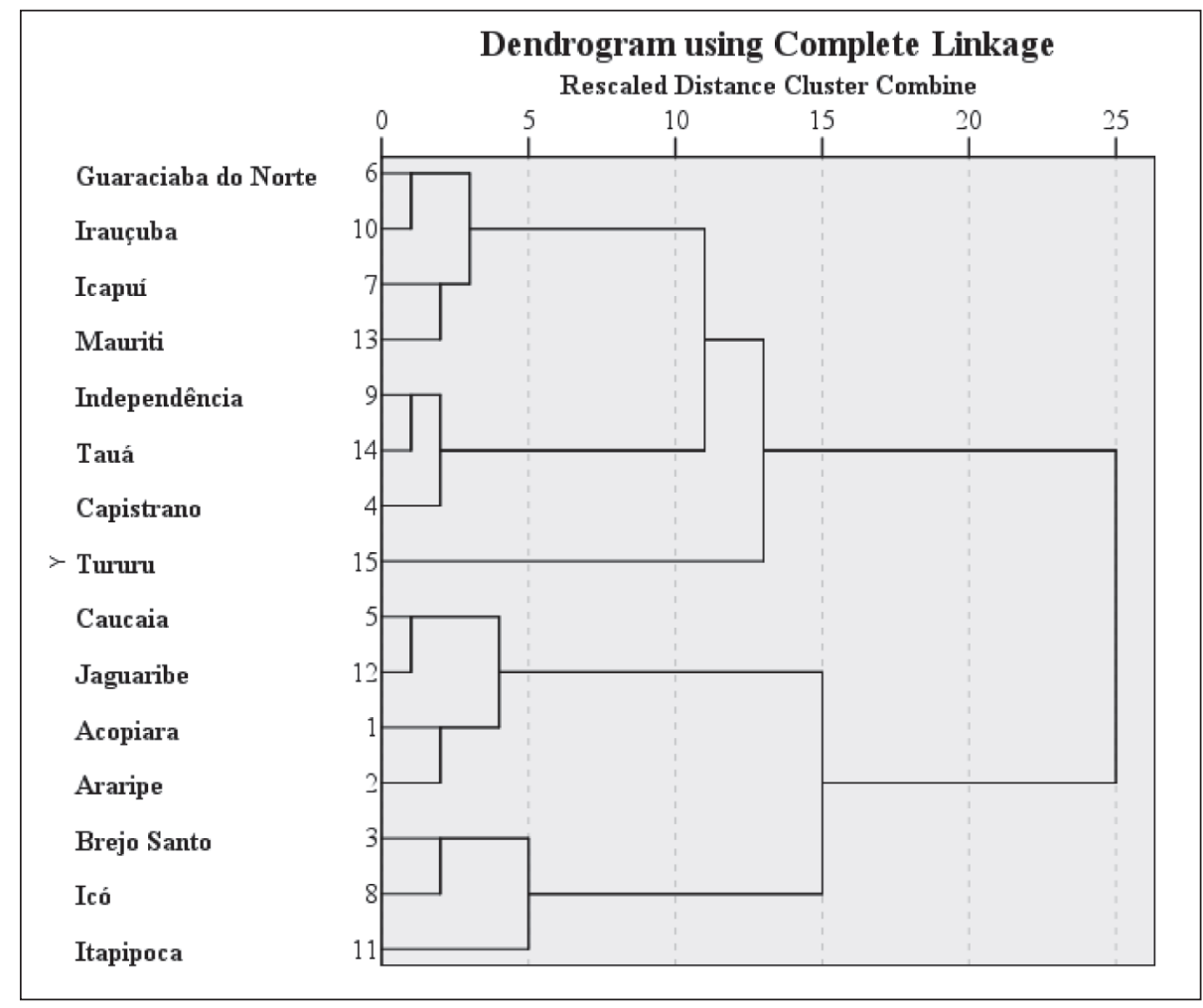

Fonte: Dados da pesquisa.

\subsection{Adesão/evasão dos alunos do PBA}

Por fim, acerca das variáveis representativas da adesão/evasão dos alunos do PBA, obteve-se o seguinte resultado com a técnica de análise de conglomerados, conforme tabela 7.

Esta última análise agruparia as observações em dois grupos, sendo eles:

Grupo 1 (13 municípios): Acopiara, Araripe, Brejo Santo, Capistrano, Caucaia, Guaraciaba do Norte, Icapuí, Icó, Independência, Irauçuba, Jaguaribe, Mauriti, Tauá.

Grupo 2 (dois municípios): Itapipoca, Tururu.

Assim como nas análises anteriores, a escolha pela quantidade de dois grupos se deu com a aplicação do critério de parada simples em momentos de elevação súbita no coeficiente 
de aglomeração. Da etapa 13 para a etapa 14 houve o maior aumento relativo desse coeficiente $(0,820$ para 1,451$)$, ficando a parada indicada no estágio 13 , cuja solução é de dois grupos.

Tabela 7

Tabela de aglomeração dos municípios (adesão/evasão dos alunos no PBA)

\begin{tabular}{|c|c|c|c|c|c|c|}
\hline & & & Agglomerati & nedule & & \multirow{3}{*}{ Next Stage } \\
\hline \multirow[t]{2}{*}{ Stage } & \multicolumn{2}{|c|}{ Cluster Combined } & \multirow[t]{2}{*}{ Coefficients } & \multicolumn{2}{|c|}{ Stage Cluster First Appears } & \\
\hline & Cluster 1 & Cluster 2 & & Cluster 1 & Cluster 2 & \\
\hline 1 & 4 & 8 &, 058 & 0 & 0 & 8 \\
\hline 2 & 5 & 6 & ,099 & 0 & 0 & 9 \\
\hline 3 & 11 & 15 &, 115 & 0 & 0 & 14 \\
\hline 4 & 1 & 14 &, 121 & 0 & 0 & 8 \\
\hline 5 & 10 & 12 &, 141 & 0 & 0 & 7 \\
\hline 6 & 2 & 3 &, 143 & 0 & 0 & 11 \\
\hline 7 & 9 & 10 &, 188 & 0 & 5 & 10 \\
\hline 8 & 1 & 4 &, 226 & 4 & 1 & 11 \\
\hline 9 & 5 & 7 & 260 & 2 & 0 & 10 \\
\hline 10 & 5 & 9 &, 370 & 9 & 7 & 12 \\
\hline 11 & 1 & 2 & ,384 & 8 & 6 & 13 \\
\hline 12 & 5 & 13 & 637 & 10 & 0 & 13 \\
\hline 13 & 1 & 5 & 820 & 11 & 12 & 14 \\
\hline 14 & 1 & 11 & 1,451 & 13 & 3 & 0 \\
\hline
\end{tabular}

Fonte: Dados da pesquisa.

Mesmo que essa diferença significativa na quantidade de municípios entre os grupos possa parecer intrigante, com a interpretação dos dois grupos encontrados, observa-se que essa solução caracteriza-se através de uma relevante diferença entre os grupos, tendo em vista a distância reescalonada presente entre os dois grupos - no Grupo 1 é próxima a 15 e no Grupo 2 é de apenas 2 - conforme a figura 5.

Conforme apontado pelos alfabetizadores, os municípios de Itapipoca e Tururu, que foram alocados no Grupo 2, foram os que mais perceberam uma continuidade dos estudos por parte dos alunos alfabetizados, com 61,45\% dos alfabetizadores afirmando que mais da metade dos alunos continuaram os estudos. Para os demais municípios, agrupados no Grupo 1 , as maiores médias de resposta ficaram entre aqueles que não sabem informar $(26,93 \%)$ ou que afirmam que os alunos não continuaram os estudos (15,75\%). Além disso, esses municípios do Grupo 1 apresentaram média de evasão maior do que os do Grupo 2 (74,69\% contra $25,22 \%$ ), sendo as principais causas apontadas pelos alfabetizadores o fato de alguns alunos apresentarem deficiências visuais ou auditivas (40,75\%) ou motivos de trabalho $(31,58 \%)$. 
Figura 5

Dendrograma (adesão/evasão dos alunos do PBA)

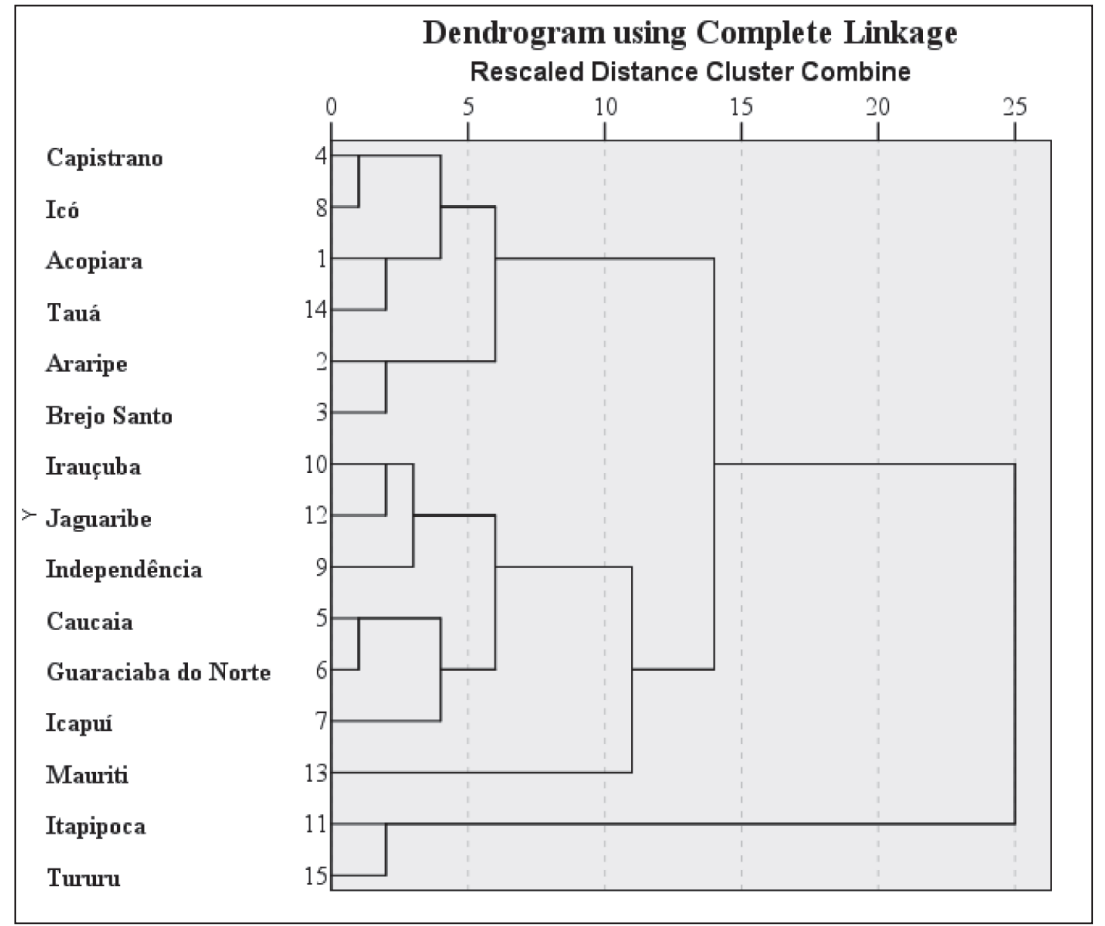

Fonte: Dados da pesquisa.

Em suma, com a aplicação da técnica de conglomerados, foi possível analisar o PBA em cada um dos municípios da amostra. Assim, o quadro 3 apresenta os grupos construídos ao longo da análise quantitativa e suas principais características relativas a cada um dos fatores considerados para apreciação.

Quadro 3

Visão geral dos grupos de municípios obtidos na pesquisa

\begin{tabular}{|c|c|c|c|c|}
\hline \multirow{2}{*}{$\begin{array}{l}\text { FATORES DE } \\
\text { ANÁLISE NA } \\
\text { PESQUISA }\end{array}$} & \multicolumn{4}{|c|}{ MUNICÍPIOS E PRINCIPAIS CARACTERÍSTICAS } \\
\hline & & GRUPO 1 & & GRUPO 2 \\
\hline $\begin{array}{l}\text { Currículo do } \\
\text { alfabetizador }\end{array}$ & $\begin{array}{c}\text { ACO, ARA, BRE, } \\
\text { GUA, ICO, ITA, } \\
\text { MAU, TUR. }\end{array}$ & $\begin{array}{l}\text { Alfabetizadores selecionados } \\
\text { por entrevistas e currículo, } \\
\text { com participação posterior em } \\
\text { cursos de formação. }\end{array}$ & $\begin{array}{l}\text { CAP, CAU, ICA, } \\
\text { IND, IRA, JAG, } \\
\text { TAU. }\end{array}$ & $\begin{array}{l}\text { Alfabetizadores selecionados } \\
\text { por provas e indicação, sem } \\
\text { participação posterior em } \\
\text { cursos de formação. }\end{array}$ \\
\hline $\begin{array}{l}\text { Curso de } \\
\text { formação de } \\
\text { alfabetizadores }\end{array}$ & ACO, ARA, ICO. & $\begin{array}{l}\text { Cursos deficientes quanto à } \\
\text { carga horária. }\end{array}$ & $\begin{array}{l}\text { BRE, CAP, CAU, } \\
\text { GUA, ICA, IND, } \\
\text { IRA, ITA, JAG, } \\
\text { MAU, TAU, TUR. }\end{array}$ & $\begin{array}{l}\text { Cursos deficientes quanto ao } \\
\text { material didático e instrutores. }\end{array}$ \\
\hline
\end{tabular}




\begin{tabular}{|c|c|c|c|c|}
\hline \multirow{2}{*}{$\begin{array}{l}\text { FATORES DE } \\
\text { ANÁLISE NA } \\
\text { PESQUISA }\end{array}$} & \multicolumn{4}{|c|}{ MUNICÍPIOS E PRINCIPAIS CARACTERÍSTICAS } \\
\hline & & GRUPO 1 & & GRUPO 2 \\
\hline $\begin{array}{l}\text { Atuação da } \\
\text { coordenação } \\
\text { dos cursos }\end{array}$ & $\begin{array}{l}\text { ACO, ARA, BRE, } \\
\text { CAP, CAU, GUA, } \\
\text { ICA, IND, JAG, } \\
\text { MAU. }\end{array}$ & $\begin{array}{l}\text { Maior frequência de visitas } \\
\text { mensais. }\end{array}$ & $\begin{array}{c}\text { ICO, IRA, ITA, TAU, } \\
\text { TUR. }\end{array}$ & $\begin{array}{l}\text { Maior frequência de visitas } \\
\text { semanais. }\end{array}$ \\
\hline $\begin{array}{c}\text { Curso de } \\
\text { alfabetização do } \\
\text { PBA }\end{array}$ & $\begin{array}{l}\text { ACO, ARA, BRE, } \\
\text { CAU, ICO, ITA, } \\
\text { JAG. }\end{array}$ & $\begin{array}{l}\text { Duração do curso suficiente } \\
\text { para alfabetização dos alunos } \\
\text { e existência de programas } \\
\text { para deficientes visuais. }\end{array}$ & $\begin{array}{l}\text { CAP, GUA, ICA, } \\
\text { IND, IRA, MAU, } \\
\text { TAU, TUR. }\end{array}$ & $\begin{array}{c}\text { Duração do curso insatisfatória } \\
\text { para alfabetização dos alunos } \\
\text { e inexistência de programas } \\
\text { para deficientes visuais. }\end{array}$ \\
\hline $\begin{array}{l}\text { Adesão/evasão } \\
\text { dos alunos do } \\
\text { PBA }\end{array}$ & $\begin{array}{c}\text { ACO, ARA, BRE, } \\
\text { CAP, CAU, GUA, } \\
\text { ICA, ICO, IND, } \\
\text { IRA, JAG, MAU, } \\
\text { TAU. }\end{array}$ & $\begin{array}{l}\text { Não ciência da continuidade } \\
\text { dos estudos dos alunos por } \\
\text { parte dos alfabetizadores } \\
\text { e alta taxa de evasão por } \\
\text { deficiências visuais e auditivas } \\
\text { e aspectos de trabalho. }\end{array}$ & ITA, TUR. & $\begin{array}{l}\text { Continuidade dos estudos por } \\
\text { parte dos alunos alfabetizados } \\
\text { e baixa taxa de evasão. }\end{array}$ \\
\hline
\end{tabular}

Fonte: Dados da pesquisa.

\section{Considerações finais}

Este trabalho teve como objetivo analisar as características do Programa Brasil Alfabetizado (PBA) - em relação a currículo do alfabetizador, curso de formação de alfabetizadores, atuação da coordenação, curso de alfabetização e adesão/evasão dos alunos, em municípios do estado do Ceará que aderiram ao programa. Conforme apontado, a importância da avaliação deste programa governamental no referido estado se justifica pelo fato de o Ceará ser um dos estados com maior taxa de analfabetismo no país - 17,19\%, conforme dados do MEC (2012). Assim, considerando ser o PBA uma importante ferramenta da política pública educacional que visa erradicar o analfabetismo do Brasil, a avaliação de suas características de ação e desempenho, realizada neste estudo mediante abordagem quantitativa, vem a construir um panorama geral que possibilita uma compreensão de algumas de suas principais características.

Com a seleção amostral de 15 municípios que, dentro dos critérios estatísticos de inferência, têm capacidade de representar a totalidade dos 167 municípios cearenses aderentes ao PBA no ano de 2010, e aplicação da técnica de análise de conglomerados nos dados obtidos, mediante questionário aplicado junto aos alfabetizadores do programa, foi possível cumprir com o objetivo proposto para este estudo.

Diante das variáveis destacadas na análise, é possível apontar algumas recomendações, tendo em vista o aprimoramento das ações do PBA nos municípios do estado. Nesse sentido, torna-se importante o fortalecimento da participação dos alfabetizadores de todos os municípios aderentes ao programa em cursos de formação continuada, de forma a permitir a manutenção e o desenvolvimento das capacidades de ensino-aprendizagem desses indivíduos, favorecendo a alfabetização dos alunos matriculados. Além disso, ressalta-se a necessidade 
de uma avaliação desses cursos de formação direcionados aos alfabetizadores, em termos de carga horária, material didático e instrutores. Assim, espera-se que, dentro da carga horária estabelecida para os cursos de alfabetização do PBA, esses alfabetizadores possam desenvolver melhor as competências dos alunos, melhorando o aproveitamento das aulas.

Da parte dos coordenadores, percebe-se a pouca frequência de suas visitas para acompanhamento in loco das atividades do PBA. Assim, torna-se necessária uma disseminação entre os coordenadores da importância dessas visitas frequentes, devendo as mesmas se realizarem, pelo menos, semanalmente. Em complemento, emerge a carência de programas para deficientes visuais e auditivos, construídos em conjunto por alfabetizadores e coordenação, com o intuito de aperfeiçoar o desenvolvimento desses alunos, reduzindo a evasão, fortemente percebida na quase totalidade dos municípios.

Por fim, como é comum a todo estudo desenvolvido dentro de uma abordagem quantitativa, é importante destacar a necessidade de pesquisas posteriores, de cunho qualitativo, que possam aprofundar os aspectos observados neste estudo, contribuindo com um maior entendimento acerca de suas causas e consequências. Além disso, mostra-se imperativa a realização de pesquisas que tenham como foco a percepção dos coordenadores, bem como dos próprios alunos matriculados no PBA, e que venham a corroborar os achados deste estudo, ou mesmo complementar as discussões apresentadas com novos elementos.

\section{Referências}

AZEVEDO, Janete M. L. de. A educação como política pública. 3. ed. Campinas: Autores Associados, 2004.

BRASIL. Lei no 10.880 de 9 de junho de 2004. Institui o Programa Nacional de Apoio ao Transporte do Escolar - PNATE e o Programa de Apoio aos Sistemas de Ensino para Atendimento à Educação de Jovens e Adultos, dispõe sobre o repasse de recursos financeiros do Programa Brasil Alfabetizado, altera o art. 4 da Lei nº 9.424, de 24 de dezembro de 1996, e dá outras providências. Disponível em: <www.planalto.gov.br/ccivil_03/_Ato2004-2006/2004/Lei/L10.880.htm>. Acesso em: 23 nov. 2013.

BRASIL. Resolução CD/FNDE no 32 de 01 de julho de 2011. Disponível em: <www.fnde.gov.br/fnde/ legislacao/item/3455>. Acesso em: 8 dez. 2012.

CORRAR, Luiz J.; PAULO, Edilson; DIAS FILHO, José M. Análise multivariada para os cursos de administração, ciências contábeis e economia. São Paulo: Atlas, 2009.

DI PIERRO, Maria C. Descentralização, focalização e parceria: uma análise das tendências nas políticas públicas de educação de jovens e adultos. Educação e Pesquisa, São Paulo, v. 27, n. 2, p. 321-37, jul./dez. 2001.

DI PIERRO, Maria C. Educação de jovens e adultos na América Latina e Caribe: trajetória recente. Cadernos de Pesquisa, v. 38, n. 134, p. 367-391, maio/ago. 2008. 
DI PIERRO, Maria C. Notas sobre a redefinição da identidade e das políticas públicas de educação de jovens e adultos no Brasil. Educ. Soc., Campinas, v. 26, n. 92, p. 1115-1139, 2005.

FARIA, Dóris S. de. Alfabetização: práticas e reflexões - subsídios para o alfabetizador. Brasília: Editora Universidade de Brasília, 2003.

FÁVERO, Luiz P. L. et al. Análise de dados: modelagem multivariada para tomada de decisões. Rio de Janeiro: Campus, 2009.

FRAGO, Antônio V. Alfabetização na sociedade e na história: vozes, palavras e textos. Porto Alegre: Artes Médicas, 1993.

FREIRE, Paulo. Alfabetização: leitura do mundo e leitura da palavra. Rio de Janeiro: Paz e Terra, 1990.

FREITAS, Henrique et al. O método de pesquisa survey. Revista de Administração, v. 35, n. 3, p. 105-112, 2000.

GIRON, Graziela R. Políticas públicas, educação e cidadania: o que isso tem a ver com cidadania? Revista de Educação PUC-Campinas, Campinas, n. 24, p. 17-26, jun. 2008.

INSTITUTO BRASILEIRO DE GEOGRAFIA E ESTATÍSTICA. Pesquisa Nacional por Amostragem de Domicílios-PNAD. IBGE, 2010. Disponível em: <www.ibge.gov.br>. Acesso em: 5 set. 2013.

MALHOTRA, Naresh. Pesquisa de marketing: uma orientação aplicada. 3. ed. Porto Alegre: Bookman, 2001.

MELLO, Guiomar N. de. Políticas públicas de educação. São Paulo: USP, Instituto de Estudos Avançados, 1991. (Série Educação para a cidadania, 1)

MINAYO, Maria C. de S.; SANCHES, Odécio. Quantitativo-qualitativo: oposição ou complementaridade? Cad. Saúde Públ., v. 9, n. 3, p. 239-262, jul./set. 1993.

MINISTÉRIO DA EDUCAÇÃO. MEC. Secretaria de Educação Continuada, Alfabetização e Diversidade — Secad. Disponível em: <http://portal.mec.gov.br>. Acesso em: 1o dez. 2012.

MINISTÉRIO DA EDUCAÇÃO. MEC. Secretaria de Educação Continuada, Alfabetização e Diversidade - Secad. Documento Nacional Preparatório à VI Conferência Internacional de Educação de Adultos (VI Confintea). Brasília: MEC; Goiânia: Funape/UFG, 2009.

MORTATTI, Mario do R. L. Alfabetização no Brasil: conjecturas sobre as relações entre políticas públicas e seus sujeitos privados. Revista Brasileira de Educação, São Paulo, v. 15, n. 44, p. 329$341,2010$.

PINTO, José M. de R. et al. Um olhar sobre os indicadores de analfabetismo no Brasil. R. Bras. Est. Pedag., v. 81, n. 199, p. 511-524, set./dez. 2000.

RUMMERT, Sonia M.; VENTURA, Jaqueline P. Políticas públicas para educação de jovens e adultos no Brasil: a permanente (re)construção da subalternidade - considerações sobre os Programas Brasil Alfabetizado e Fazendo Escola. Educ. Rev., Curitiba, n. 29, p. 29-45, 2007. 
STEINER, João E. Conhecimento: gargalos para um Brasil no futuro. Estudos Avançados, São Paulo, v. 20, n. 56, p. 75-90, 2006.

TEIXEIRA, Paula de A. P. Direito fundamental à alfabetização. Universitas/JUS, v. 23, n. 1, p. 4152, jan./jun. 2012.

UNESCO. Organização das Nações Unidas para a Educação, a Ciência e a Cultura. Alfabetização como liberdade. Brasília: Unesco, 2003.

UNESCO. Organização das Nações Unidas para a Educação, a Ciência e a Cultura. Alfabetização de jovens e adultos no Brasil: lições da prática. Brasília: Unesco, 2008.

UNESCO. Organização das Nações Unidas para a Educação, a Ciência e a Cultura. Conferência Internacional de EJA. Hamburgo: Unesco, 1999. Documento.

UNESCO. Organização das Nações Unidas para a Educação, a Ciência e a Cultura. O desafio da alfabetização global: um perfil da alfabetização de jovens e adultos na metade da Década das Nações Unidas para a Alfabetização 2003-2012. Brasília: Unesco, 2009.

WEISZ, Telma. Alfabetização no contexto das políticas públicas. In: CONGRESSO BRASILEIRO DE QUALIDADE NA EDUCAÇÃO: FORMAÇÃO DE PROFESSORES, 2002, Brasília. Disponível em: <portal.mec.gov.br/seb/arquivos/pdf/volld.pdf>. Acesso em: 10 dez. 2012.

Gleison Mendonça Diniz é doutorando em administração de empresas da Universidade de Fortaleza (Unifor).E-mail: gleisondiniz@uol.com.br.

Diego de Queiroz Machado é doutorando em administração de empresas da Universidade de Fortaleza (Unifor). E-mail: diegoqueirozm@yahoo.com.br.

Heber José de Moura é doutor em administração de empresas pela Fundação Getulio Vargas (FGV-SP) e professor titular do Programa de Pós-Graduação em Administração da Universidade de Fortaleza (Unifor). E-mail: heberm@unifor.br. 